\title{
Estudo de caso Ilha de Vera Cruz: um arquipélago de formações
}

Mara Parisi de Moura é graduada em Educação Física e Pedagogia, especialista em educação pela Pontifícia Universidade Católica de São Paulo, e orientadora pedagógica do Projeto Social Ilha de Vera Cruz (Educação de Jovens e Adultos).

Contato: orientacao.ilha@veracruz.edu.br

\section{Resumo}

Este artigo apresenta um projeto social da Escola Vera Cruz: Ilha de Vera Cruz, que oferece educação de jovens, adultos e idosos desde a alfabetização até o ensino fundamental II e a formação dos professores e monitores voluntários que atuam neste projeto. Abrange, também, o histórico, a metodologia, a concepção e a principal vertente do trabalho, ou seja, a formação qualificada dos profissionais voluntários focada em duas frentes.

Palavras-chave: Educação de Jovens e Adultos (EJA); formação de educadores; projeto social; concepção; metodologia.

\section{Abstract}

This article presents the social project of Vera Cruz School: Itha de Vera Cruz, which offers education to youth, adults and elderly from alphabetization to $8^{\text {th }}$ grade and also provides training of the volunteer teachers and assistants that take part of this project. This essay also encompasses the history, methodology, conception and the main focus of the project, which is to develop high-quality volunteer workers in education.

Keywords: Education of youth and adults; training of professionals; social project; conception, methodology. 
Dentro da Escola Vera Cruz, localizada na zona oeste da capital paulista, uma oportunidade de educação para jovens, adultos e idosos tem crescido consideravelmente. Essa modalidade nasceu de uma disciplina do ensino médio que pesquisou o entorno da escola e certificou-se da grande demanda de pessoas sem escolaridade.

Já em 2001, o Ilha de Vera Cruz passou a certificar os alunos que concluíam nele a $8^{a}$ série do ensino fundamental II. Com a missão de oferecer um ensino de qualidade e gratuito por meio de uma formação integrada que considera a diversidade de suas experiências, visando a valorização do ser humano, a autonomia e a promoção da cidadania, o llha também se propôs a trabalhar com um quadro de profissionais voluntários.

Hoje atende 140 alunos e 100 profissionais voluntários, que se dividem em disciplinas do ensino fundamental II, monitoria e aulas diversificadas nas salas de alfabetização e monitoria na recreação (lugar especialmente criado para atender, de maneira providencial, os filhos dos alunos matriculados).

Cercado de entusiasmo, empenho, dedicação e formação por todos os lados, o llha atende um público diverso e especial, tanto de alunos como professores, que se encontram num ponto de intersecção da educação imbuídos da necessidade de um trabalho significativo e qualitativo de ensino e aprendizagem.

A formação em serviço desses profissionais é uma integração de várias ações: reuniões pedagógicas quinzenais e mensais, envio e devolutiva de planejamentos e relatórios, além de assessoria permanente na orientação pedagógica.

Os alunos da alfabetização ( $1^{\mathrm{a}}$ a $4^{\mathrm{a}}$ séries do ensino fundamental I) estudam no prédio dos Correios, localizado em frente à escola, estabelecendo uma parceria importante graças à disponibilidade de duas salas de aulas e dois laboratórios de informática.

Os alunos do fundamental II utilizam-se das amplas e equipadas salas do prédio da rua Baumann, na Vila Leopoldina. Além das disciplinas básicas, o currículo é composto de áreas expressivas como teatro, cinema e fotografia, entre outros. 
0 Ilha de Vera Cruz se rende à formação intrínseca e vivencial de cada cidadão envolvido no projeto, para além das letras, números e "quetais", para além do esforço, do trabalho, das teorias e concepções. Para muito mais que se pode vivenciar enquanto gente, cidadão, ser humano no mais humano das palavras.

\section{A formação do professor voluntário}

Este projeto tomou nas mãos a responsabilidade e o compromisso de unir dois grandes desafios: alfabetizar adultos e contribuir para a solidificação do trabalho voluntário na área de educação de jovens, adultos e idosos.

A formação do professor nesse projeto é parte fundamental e um princípio de cidadania no qual o profissional voluntário se envolve, compreendendo todas as responsabilidades e regras do trabalho, e a instituição acolhe esse profissional, procurando compreender as suas expectativas. Uma formação que exige empenho, tanto no significado do trabalho voluntário quanto no exercício da prática docente específica para jovens, adultos e idosos.

Fundamenta-se no conceito de um trabalho voluntário responsável, comprometido e submetido a todas as exigências necessárias no mundo da educação. Os profissionais voluntários são, em primeiro lugar, educadores desta instituição e, por isso, devem portar-se como tal: elaborando planejamentos, relatórios de aulas, pesquisas, leituras, participação em reuniões pedagógicas quinzenais e reuniões formativas mensais, além de participar dos eventos escolares e estudos do meio. Tem um valor incomensurável, pois é imprescindível para que o projeto aconteça com a qualidade de educação que acreditamos.

Segundo Paulo Freire (1987) "(...) a educação se re-faz constantemente na práxis. Para ser tem que estar sendo" (p. 73). Identificado com esta concepção, o Ilha de Vera Cruz iniciou um trabalho desafiador e foi se revendo dia após dia.

Ao buscar entender como o adulto aprende e quais são as suas expectativas em relação ao estudo, as reflexões naturalmente se encaminharam para as competências e habilidades necessárias para a formação de um professor de EJA, principalmente se tratando de profissionais voluntários que, em muitos casos, não têm formação específica na área de educação. Neste sentido, os investimentos realizados estavam relacionados à apresentação e 
discussão das metodologias existentes, estudo e reflexão sobre a didática específica para esse público, indicação e estabelecimento de parcerias interdisciplinares, sempre pautados numa concepção socioconstrutivista, contemplando os teóricos da área e abordando, também, outras concepções para estabelecer relações e perceber qual a prática mais plausível para a constituição e permanência deste trabalho.

Paralelamente ao trabalho de formação do professor, questões importantes surgiram, tais como: a) que tipo de educação acreditamos e queremos oferecer?; b) qual a metodologia mais adequada para o trabalho com adultos?

No que diz respeito à primeira questão, a proposta educacional do Ilha de Vera Cruz está pautada no objetivo de formar alunos intelectualmente ativos, que comparem, excluam, categorizem, formulem, reformulem e comprovem hipóteses. Sujeitos que possam compreender no lugar de memorizar, que tenham compreensão do como no lugar da reprodução do o quê, que aprendam pela ação sobre o objeto.

Acreditando que "ninguém nasce feito. Vamos nos fazendo aos poucos, na prática social de que tomamos parte" (Freire, 2001, p.79), o Ilha de Vera Cruz procura favorecer um ambiente no qual os alunos possam se manifestar. Um ambiente em que as vozes sejam ouvidas, os alunos se posicionem e reflitam sobre seus desejos e possibilidades.

No que diz respeito à segunda questão, o Ilha de Vera Cruz tem trabalhado com o que se chama abordagem integradora dos métodos. Uma metodologia baseada no movimento curiosidade/ busca/descoberta, permitindo e estimulando a ação/reflexão/ ação. Considera os aspectos cognitivos, afetivos, sociais e culturais dos alunos, juntamente com suas especificidades. Respeita e considera a diversidade da formação acadêmica dos professores que devem comprometer-se na busca e construção (aprender, renovar/repensar a prática) e na mediação (olhar, ouvir, interagir, trocar, questionar, auxiliar, favorecer, criar condições) das situações de aprendizagem. Uma abordagem que auxilia os alunos em suas necessidades específicas, contrapondo com outras metodologias (tradicional, renovada montessoriana, tecnicista, libertadora, piagetiana, freiriana) para estabelecermos parâmetros de comparações e avaliações sobre o que e como poderíamos abordar alguns encaminhamentos de cada uma delas em benefício da aprendizagem do aluno que carrega hábitos e comportamentos já estabelecidos culturalmente e precisam ser respeitados. Ou seja, 
uma abordagem que se apropria das diferentes metodologias, mas que resguarda sua concepção.

Entendemos por abordagem integradora dos métodos uma proposta que valoriza a diversidade de estratégias encontradas nos diferentes métodos existentes, de modo a favorecer o aluno, respeitando seu ritmo de aprendizagem, sua maneira própria de se apropriar do conhecimento e mantendo o foco no comprometimento do aprender.

Com base nessas premissas, o llha de Vera Cruz se dedicou fortemente na formação continuada de seus professores, buscando atender a especificidade do trabalho com jovens, adultos e idosos, e também a especificidade do trabalho com o professor voluntário, que carrega um estigma de falta de seriedade e compromisso.

Há duas frentes de formação: a) o que é o trabalho voluntário, suas raízes, sua evolução, seus objetivos, sua seriedade; b) formação pedagógica, que contempla didática, metodologia e conteúdo curricular.

A formação de professores no llha de Vera Cruz também procura trabalhar a difícil questão do estabelecer uma liģação entre os conteúdos curriculares e o cotidiano do aluno. É um engano acreditar que qualquer tema é de interesse dos alunos. As conexões sobre meio ambiente, doenças, controle de natalidade podem virar simples jargões e desmotivar os alunos. A pergunta "Para que serve o que estou aprendendo?", se não está explicitamente feita, com certeza se apresenta de forma implícita em todos os momentos em uma sala de aula para jovens, adultos e idosos. Não é fácil o professor dar resposta para essa pergunta, sem cair em clichês. É necessário que o professor mostre que não se trata de decorar, mas de desenvolver habilidades de raciocínio.

Deixar essa questão clara só é possível aproximando-se dos interesses dos alunos e é isso que a formação de professores no Ilha de Vera Cruz vem se propondo a fazer com as estratégias apontadas. Diante de um aluno que só consegue formar a palavra de maneira silabada (método tradicional), aproveitamos do contexto em que a atividade está inserida e propomos que ele monte a palavra com as sílabas. Isto não quer dizer que trabalhamos de forma tradicional, mas que consideramos como o aluno aprende para que ele se aproprie daquele contexto. Consideramos que monte as contas de forma decorada, mas explicaremos como se dá esse caminho; então, ele poderá continuar montando daquela maneira, mas aprenderá o percurso. 
E se o aluno não consegue entender como as contas são feitas, apresentaremos as mesmas sob as mais diversas formas: material dourado, material de contagem, conta armada, tabuada, calculadora, até que ele compreenda uma das formas.

Estamos inseridos num mundo que avalia os alunos tradicionalmente, por meio de notas, boletins e provas. Trabalhamos num sentido de contemplação dessa tradição, mas, ao mesmo tempo, imbuídos de uma concepção autônoma e cidadã. Apesar de parecer contraditório, é possível, real e traduz nosso trabalho.

Além dos subsídios criados pelos orientadores pedagógicos, a formação dos professores no Ilha de Vera Cruz se beneficia da parceria com o Instituto Superior de Educação - ISE Vera Cruz, sediado na mesma instituição. Na parceria estabelecida, professores voluntários podem assistir a aulas de graduação como ouvintes. Há critérios claros para a concessão desse benefício no processo de formação e nossos professores se favorecem de uma graduação que tem uma concepção socioconstrutivista, levando esclarecimentos, explorando as diferentes didáticas, incorporando ao trabalho do Ilha uma formação acadêmica exemplar.

A permanente preocupação com a formação dos professores voluntários ajudou a criar o hábito de refletir sobre as práticas adotadas em sala de aula. Essa reflexão sempre foi colocada pela coordenação do projeto num lugar onde pudesse dialogar com as práticas existentes em outras escolas ou projetos de educação de jovens e adultos, e também com as concepções encontradas em documentos oficiais que tratam desse segmento de ensino, todas elas ressaltando a qualificação do ensino para este segmento, tanto público e privado, quanto o conhecimento proveniente de organizações não governamentais.

0 segmento é regulamentado pelo artigo 37 da Lei de Diretrizes e Bases da Educação Nacional (a LDBN, ou lei n 9394, de 20 de Dezembro de 1996). É um dos segmentos da educação básica que recebem repasse de verbas do Fundo de Manutenção e Desenvolvimento da Educação Básica e de Valorização dos Profissionais da Educação, o Fundeb.

Além de ser regulamentado, o segmento é discutido em fóruns estaduais, congressos nacionais e internacionais, como a Conferência Internacional de Educação de Adultos (Confintea), evento realizado de 12 em 12 anos a fim de aprimorar o ensino, a capacitação dos professores, e discutir temas próximos, como a evasão escolar, entre outros. 
0 trabalho com formação não se esgota e se caracteriza pela persistência, curiosidade e compromisso com a educação. Sendo assim, é importante que o professor de EJA compreenda a necessidade de estabelecer parceria com seus alunos, comprometendo-se com as responsabilidades do processo de ensino e aprendizagem. Que ele tenha clareza de seu papel nessa relação, que pressupõe reconhecer as dificuldades dos alunos e as suas próprias, de modo que busque estratégias para ajudar os alunos, mas também reconheça suas dificuldades e busque respostas além de suas referências tradicionais. A busca pela inovação precisa estar presente e convivendo harmoniosamente com nossas convicções.

\section{REFERÊNCIAS}

CIAMPA, A. da C. A estória do Severino e a história da Severina. São Paulo, Brasiliense, 2001.

CORTELLA, M. S. A escola e o conhecimento: fundamentos epistemológicos e políticos. São Paulo, Cortez, 2002.

FREIRE, P. Pedagogia da indignação: cartas pedagógicas e outros escritos. São Paulo, Unesp, 2000.

Pedagogia do oprimido. Rio de Janeiro, Paz e Terra, 1987.

Política e educação. São Paulo, Cortez, 2001.

A importância do ato de ler: em três artigos que se completam.

São Paulo, Cortez, 2003.

HELLER, A. O cotidiano e a história. São Paulo, Paz e Terra, 2000.

PAIM, J. F. Há vida para além da sala de aula: um estudo sobre a identidade do aluno de EJA. Dissertação de Mestrado, PUC, 2005.

PAIVA, V. P. Educação popular e educação de adultos. São Paulo. Loyola, 1973. 